
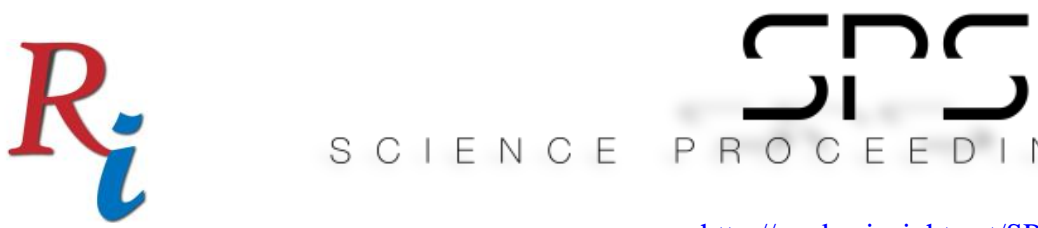

SCIENCE PROCEEDINGS SERIES

http://readersinsight.net/SPS

\title{
THERAPEUTIC EXPOSURE OF DIABETIC BLOOD USING 532 NM-WAVELENGTH LOW LEVEL LASER THROUGH ELECTRICAL IMPEDANCE SPECTROSCOPY (EIS).
}

\author{
Sylvester J. Gemanam* \\ School of Physics, Universiti Sains Malaysia, 11800, Pulau Pinang \\ Malaysia. \\ Department of Physics, Faculty of Science, Benue State University \\ P.M.B.102119, Makurdi \\ Nigeria. \\ gemanamsly@gmail.com \\ Nursakinah Suardi \\ School of Physics, \\ Universiti Sains Malaysia, 11800, Pulau Pinang \\ Malaysia. \\ nsakinahsuardi@usm.my \\ Stephanie M. Adelusi \\ Department of Physics, Faculty of Science, \\ Benue State University, P.M.B.102119, Makurdi \\ Nigeria. \\ astephanie@bsum.edu.ng \\ Daniel Terver \\ Department of Physics, Faculty of Science, \\ Benue State University, P.M.B.102119, Makurdi \\ Nigeria. \\ Terver.daniel@yahoo.co.uk
}

*Corrosponding author's Email: gemanamsly@gmail.com

Peer-review under responsibility of $4^{\text {th }}$ Asia International Multidisciplinary Conference 2020 Scientific Committee http://connectingasia.org/scientific-committee/

(C) 2020 Published by Readers Insight Publisher, lat 306 Savoy Residencia, Block 3 F11/1,44000 Islamabad. Pakistan,

editor@readersinsight.net 

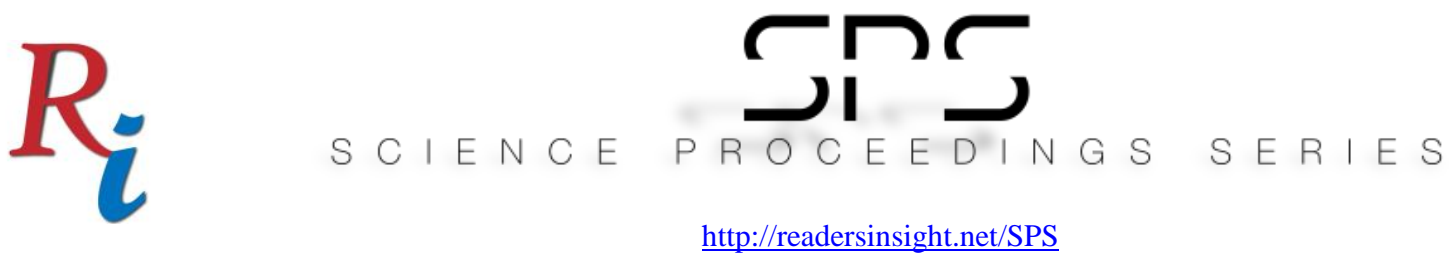

\section{A b s t r a c t}

Prior information of blood dielectric properties is important and a valuable tool to examine cell morphological structures, functions and mechanisms of their metabolic systems; however, this is under investigated. The study explores the technique of electrical impedance spectroscopy (EIS) measurements to reveal the proper biostimulation conditions for diabetic blood-low level laser therapy. Dielectric spectroscopy of the diabetic patient's blood was studied using Impedance analyser (Agilent 4294A) within the range of frequency $40 \mathrm{~Hz}-30 \mathrm{MHz}$. Blood biostimulations were done using a $532 \mathrm{~nm}$-wavelength solid-state laser (diode-pumped). The impedance characteristics of the irradiated diabetic blood and from proper analysis and observations at $50 \mathrm{~mW}$ power output within irradiation duration of 10-15 minutes yield an efficient biostimulation and positively enable rejuvenation and proliferation of the deformed erythrocytes and stimulate healthy blood condition. The irradiated diabetic blood got rejuvenated and had polarization of the electrodes ( $\alpha$-dispersion region) spanned from frequency of $40 \mathrm{~Hz}$ until reached $11.7-11.9 \mathrm{kHz}$ range comparable to the healthy human blood. The stimulation formed a positive result of the accurately biostimulated diabetic blood with significant impedance within the cell structures, cytoplasm and plasma of the blood.

\section{Rese a r ch H igh I ight s}

Electric impedance spectroscopy measurement error increases with dielectric properties variation of the diabetic blood constituents such as; erythrocytes, cell membranes, plasma contents etc. Biostimulation with $532 \mathrm{~nm}$ wavelength low level laser, the ionic polarization and dipolar effects were observed within the lower frequency range.

Blood stimulation with $50 \mathrm{~mW}$ power output laser within 10-15 minutes, the exposed diabetic blood were noticed to recover positively its morphology structure and physiological conditions therefore became rejuvenated. Higher exposures more than 15 minutes resulted to crenation and formed notch due to excessive heating therefore bio- inhibit and deteriorated.

The low intensity laser stimulation have positive biostimulation effects, increase the ATP synthesis, cell impedance of irradiated diabetic-blood and healthful state as a non-invasive therapy. 

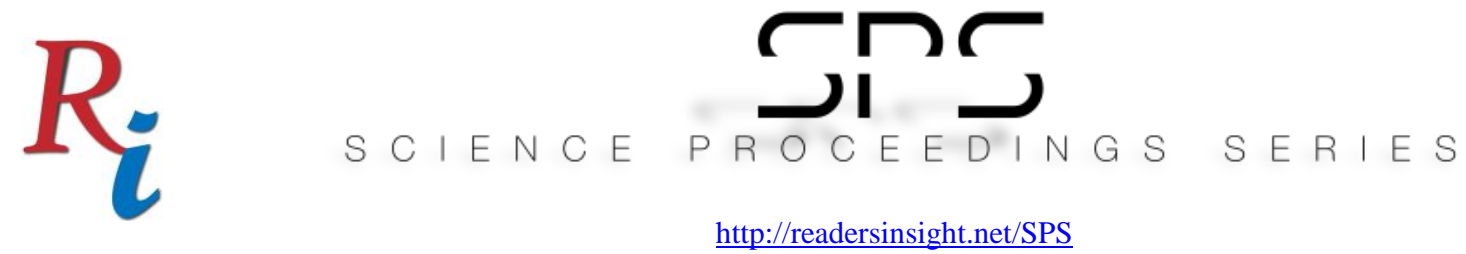

Graphic a I A b s tract
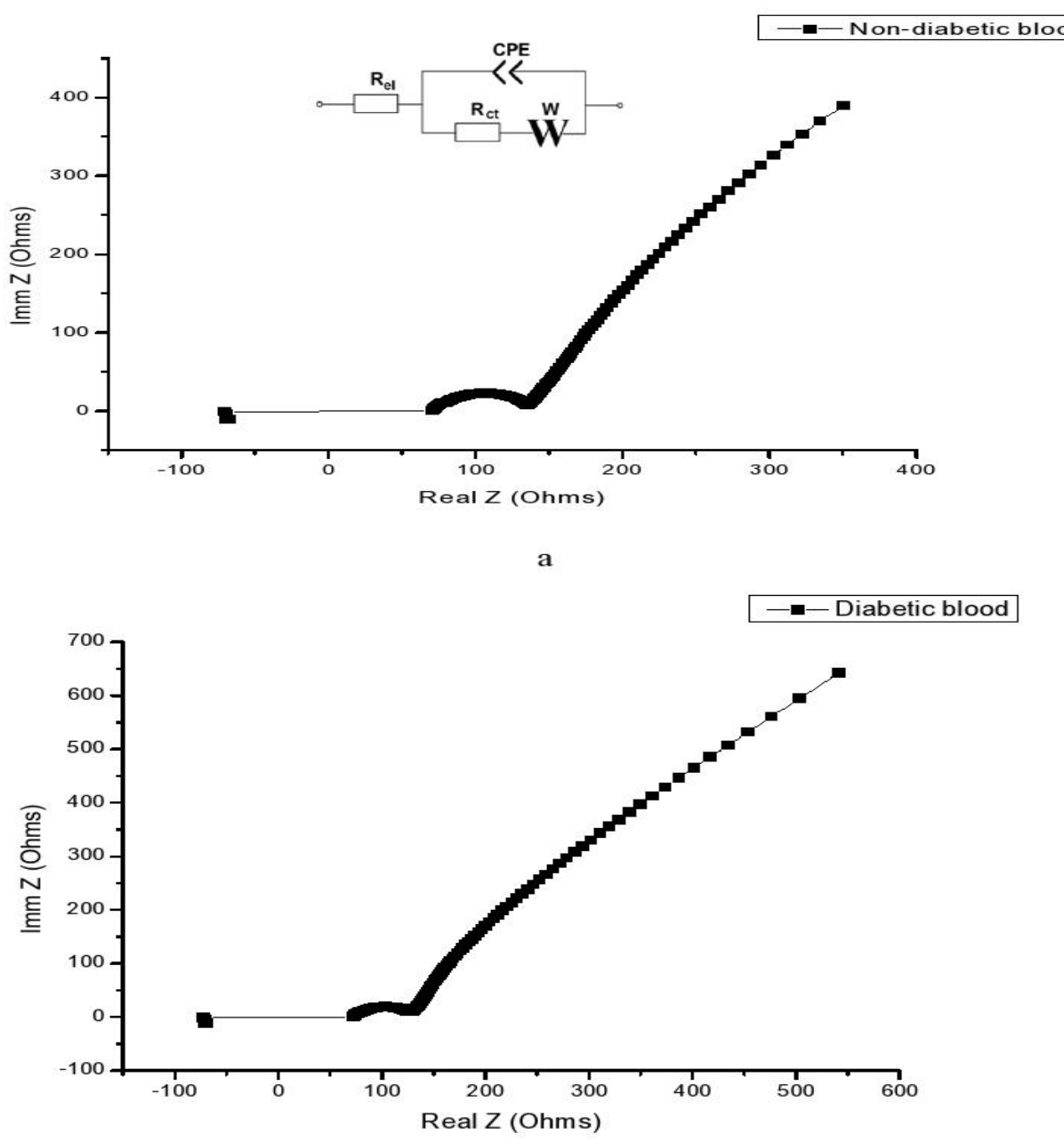

b

Fig. 1: Nyquist plots of a) normal and b) control diabetic blood-impedance with two-electrodes technique with modified Randle's circuit showing various dispersions at different fequency ranges.

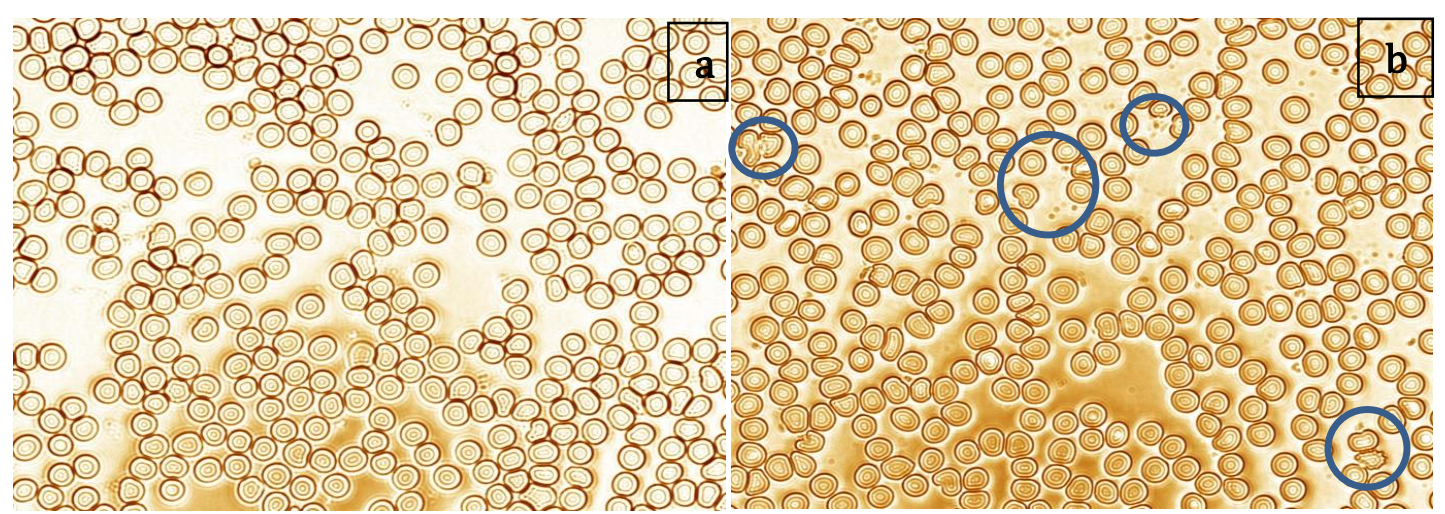

Figure 2a) Smeared control non-diabetic blood morphology and b) diabetic blood morphology showing bloats RBCs, immatured RBCs and some blast cells in blue circle. Magnifications 40X 

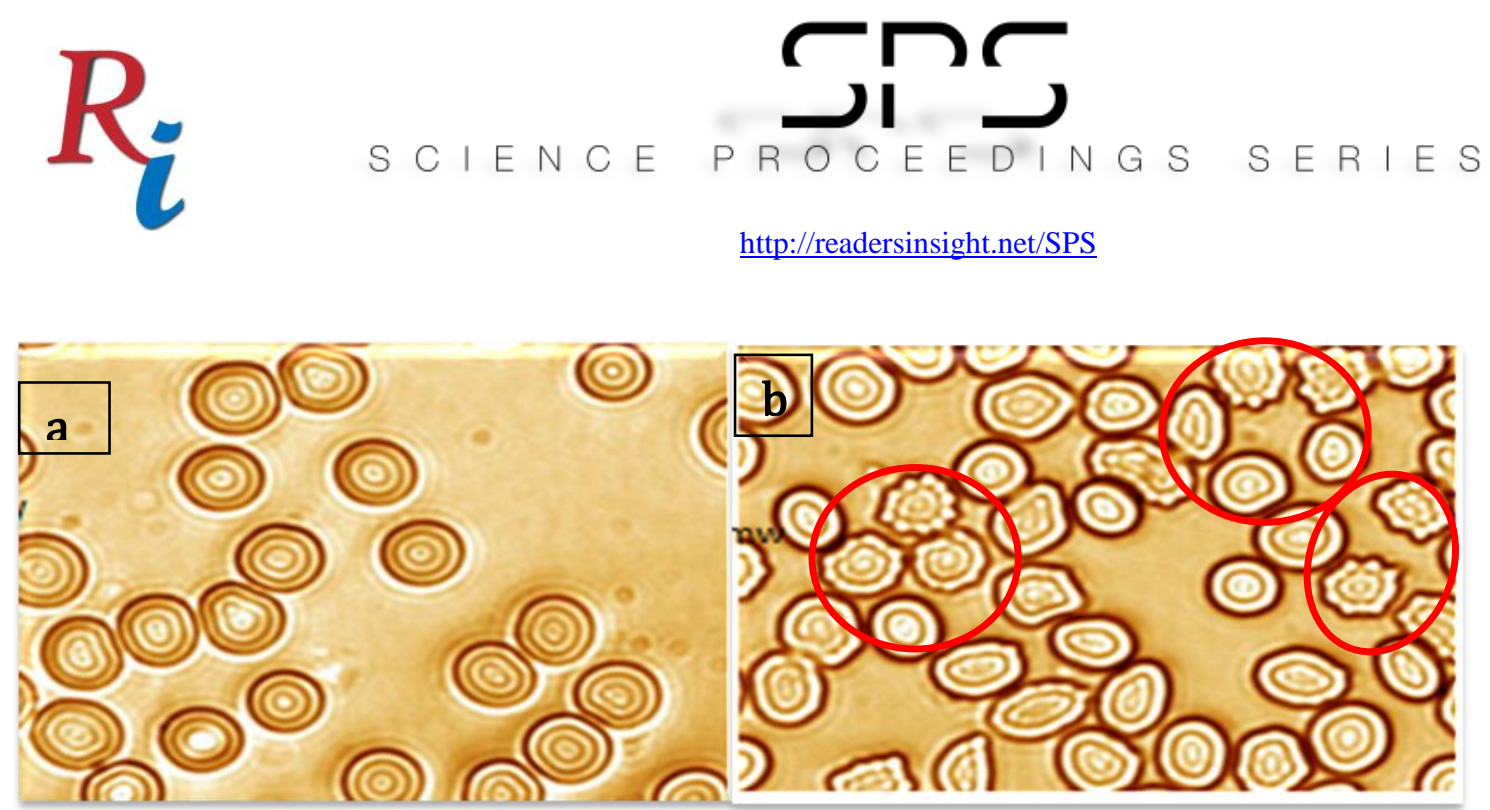

Figure 3a) Smeared diabetic blood irradiated within 10-15 minutes and b) smeared diabetic blood irradiated $>15$ minutes durations showing cell crenation due to excessive radiation, using laser power output of $50 \mathrm{~mW}$. Magnifications 100X.

\section{Research Objectives}

The work aim is to determine the biostimulation effects of low-level laser irradiation on diabetic blood through dielectric permittivity and its electrical impedance with the help to optimize the laser exposure treatment threshold to avoid bio-inhibition but encourage diabetic blood therapy. The objectives are to use the electrical impedance spectroscopy in studying the dielectric parameters in normal and diabetic blood induced by low level laser. To study the impedance levels of bio-stimulated blood then compare the dielectric response to suggest the appropriate exposure parameters for optimal laser therapy. The significant of the research is to elucidate information that will aid in the future development of non-invasive therapy for the effective treatment of diabetic mellitus (blood) using low level laser.

\section{Methodology}

\section{Blood sample collection and physiological examinations.}

Total of 84 patients were involved in the study and 8 millilitres each of their blood extacted from Universiti Sains Malaysia (USM), Wellness Centre, Penang, Malaysia under Human Ethics aceeptance via JePEM, USM, reference no. USM/JePeM/16060208. The participants included (Group 1 of 42 non-diabetic blood: Males were 27 and 15 Females non-pregnant and Group 1 of 42 diabetic blood: Males were 23 and 19 Females non-pregnant) patients of age range 24-54 years, mean age of 44 old. The glucose level range of the diabetic blood was 7.8$11.3 \mathrm{mmol} / \mathrm{L}$. the collected blood were from patients without serious blood related disease or on medication. A wavelength of $532 \mathrm{~nm}$ laser (solid state ) with beam spot of $4.0 \mathrm{~mm}$ was used for the diabetic blood irradiation on $1.26 \times 10^{-5} \mathrm{~m}^{2}$ area, intensity of $3968.254 \mathrm{~W} / \mathrm{m}^{2}$ (for 50 $\mathrm{mW}$ ). The Irradiation was done for durations of 5, 10, 15 and 20 minutes for the irradiated 

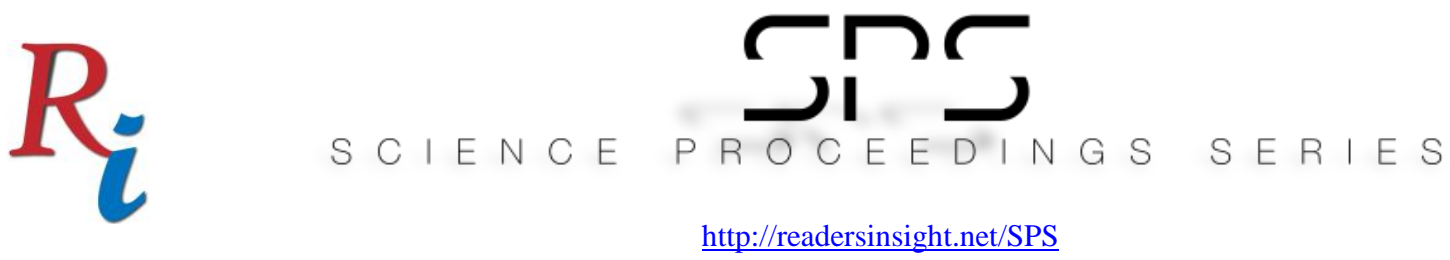

samples. Designed cuvettes contained the blood samples that measurements were carriedout before and after irradiated. The electrodes areas in collected samples was $\mathrm{A}\left(0.36 \mathrm{~cm}^{2}\right)$ each with gap between of $\mathrm{d}(=0.59 \mathrm{~cm})$, volume of blood sample in the conductivity cell was 1 millilitre[2-4].

\section{Spectroscopy Readings and Analysis of Dielectric Parametrs.}

An Impedance analyser (Agilent 4294 A) of $40 \mathrm{~Hz}-30 \mathrm{MHz}$ frequency range was used for the blood impedance measurements [6-7] by connecting the electrodes of the designed cuvettes to it though medium Kelvin clip lead. Records of blood capacitance and loss-energy of the samples were obtained, then further analysis and evalaution for the dielectric properties; dielectric permittivity $\varepsilon^{\prime}$, loss $\varepsilon^{\prime \prime}$, conducttivity and blood impedance.

\section{Results}

The tedency of declined impedance with respect to inceased in field frequency enables different dispersions behaviors across the erythrocyte membranes and more blood components. The result elucidates the heterogeneous characteristization of blood as demonstrated mostly $\alpha$ and $\beta$-dispersions at the reduced frequency range as in Figure 1. From Nyquist plots of the normal blood impedance decreased with square root of the frequency within the range of $40 \mathrm{~Hz}-11.7$ $\mathrm{kHz}$, while $40 \mathrm{~Hz}-17.6 \mathrm{kHz}$ for diabetic blood. This demonstrates effect of the electrodeelectrolyte interface called $\alpha$-dispersion. They exists $\beta$-dispersion from the end region of $\alpha$ dispersion to $10.2 \mathrm{MHz}$ in non-diabetic blood while spanned within $17.6 \mathrm{kHz}-11.6 \mathrm{MHz}$ formed pressed-down semi-circle and decreased effective-resistance in diabetic blood. There exists continious effect of water-electrical charge storage ability in blood sample from the crest of the pressed-down semi-circle to the measured end of the fequency range (30 MHz).

Diabetic blood has high conductivity due to precarious erythrocytes compared to the normal blood. Photo-response of blood components, white blood cells, platelet, blood plasma, and the red blood cells etc, revealed that these erythrocytes are the major photo-receptors of photons on the cellular level[1].

Irradiated diabetic blood within 10 and 15 minutes (Figures $2 \& 3$ ) demonstrated electrode polarizations at $40 \mathrm{~Hz}-11.7 \mathrm{kHz}$ and $40 \mathrm{~Hz}-11.9 \mathrm{kHz}$ frequency range respectively. The esulted impedance significantly appreciated with the least observedconductivity responses. There is formidable erythrocyte membrane at ionic polarization and siginificant impedance mechanisms comparable to the diabetic blood under controlled. 


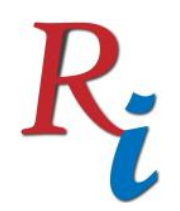

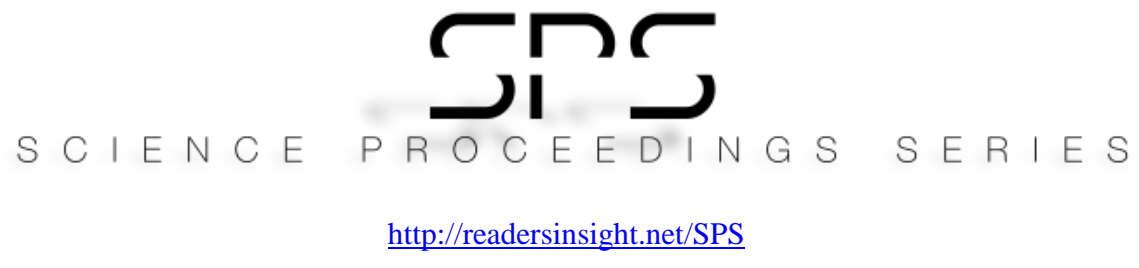

http://readersinsight.net/SPS

\section{Findings}

The blood impedance magnitude decreased with increased frequency range at applied electric field accross the erythrocytes membranes and cells cytoplasms.

Diabetic blood stimulated with $50 \mathrm{~mW}$ power output for 10-15 minutes were observed with accurate characterization of the impedance level to yield an optimal biostimulation effect. The polarization at the electodes ( $\alpha$-dispersion region) occurred within $40 \mathrm{~Hz}$ to $11.7-11.9 \mathrm{kHz}$ frequency range equally to that of the normal and healthy blood. The membrane-bound haemoglobin interaction with laser photons rejuvenate and enhanced erythrocytes morphology and buildup cell membrane. This improves blood physiological conditions, appreciable impedance of the cytoplasm and in plasma, overall moderated adequately the glucose concentration therefore prevents the $\mathrm{K}^{+}$ion efflux. Exposure beyond acceptable threshold (Figure 3b) intigates mitogenic motivation likewise lessening of lymphocytes consequently obstructs the stimulus mechanisms therefore causes deterioration.

\section{Acknowledgement}

The authors wish to acknowledge the Tertiary Education Trust Fund, Nigeria (TET Fund) and Fundamental Research Grants (FRGS/203.PFIZIK.6711598) for their sponsorship role, also Lisa Vangohol Jande for assistance throughout the data collection.

\section{REFERENCES}

[1] Gonchukov SA, Lazarev YB. Laser refractometry in medicine and biology. Laser physics. 2003;13(5):749-55.

[2] Chang ZY, Pop GA, Meijer GC. A comparison of two-and four-electrode techniques to characterize blood impedance for the frequency range of $100 \mathrm{~Hz}$ to $100 \mathrm{MHz}$. IEEE Transactions on Biomedical Engineering. 2008 Feb 15;55(3):1247-9.

[3] Fricke H, Morse S. The electric resistance and capacity of blood for frequencies between 800 and 41/2 million cycles. The Journal of general physiology. 1925 Nov 20;9(2):153.

[4] Grossi M, Parolin C, Vitali B, Riccò B. Electrical Impedance Spectroscopy (EIS) characterization of saline solutions with a low-cost portable measurement system. Engineering Science and Technology, an International Journal. 2019 Feb 1;22(1):102-8.

[5] Kim M, Kim A, Kim S, Yang S. Improvement of electrical blood hematocrit measurements under various plasma conditions using a novel hematocrit estimation parameter. Biosensors and Bioelectronics. 2012 May 15;35(1):416-420. 

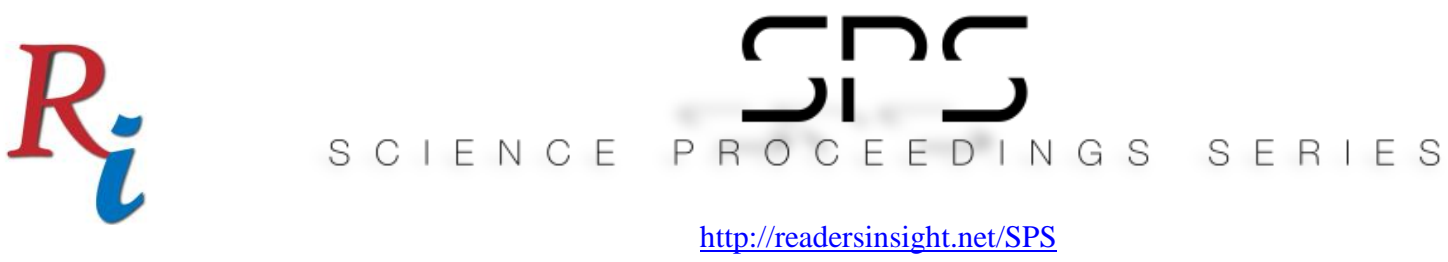

[6] Gemanam, S. J., Suardi, N., Mokmeli, S. and Mustafa, I.S, (2020), Evaluation of the proper level of specific absorption rate of human blood for $532 \mathrm{~nm}$ laser in blood lowlevel laser therapy, Laser Phys. 30 (2020) 035601, 1-9.

[7] Adam GO, Park BY, Choi KM, Kang HS, and Kim GB. Effects of Ultraviolet Blood irradiation in a Diabetes Rabbit Model, Journal of Diabetes and Obesity.2016, volume $3(2): 45-57$.

Author's Biography

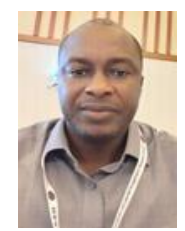

Sylvester Jande Gemanam is an Academician and researcher. B.Sc. Physics \& M.Sc. Radiation and Medical Physics (Benue State University, Makurdi, Nigeria (BSU,MKd)) then did his Ph.D. pre-Vica Voce in Radiation and Medical Physics (Universiti Sains Malaysia, Penang,Malaysia). A lecturer in the department of Physics, BSU, Mkd.

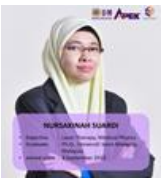

Nursakinah Suardi is a renouced researcher and Senior Lecturer in School of Physics, USM, Penang, Malaysia. She acquired her B.Sc, M.Sc \& Ph.D. Medical Physics in USM, Malaysia.

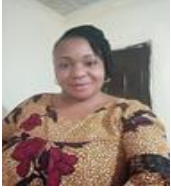

Stephanie Mdzuami Adelusi is a Researcher. B.Sc Zoology (Ahmadu Bello University, Zaria, Nigeria), M.Sc. Conservation Biology (Uni. Jos, Nigeria) and Ph.D. Applied Entomology (BSU, Mkd). She is currently a Senior Lecturer at the Department of Biological Sciences, BSU,Mkd, Nigeria. She develop much interest in interdisciplinary research in most areas of physical sciences.

Daniel Terver is a renouced Nuclear and Radiation Physicist, a Lecturer in BSU, Mkd Nig. B.Sc. Physics \& M.Sc.Theoretical Physics (BSU, Mkd, Nigeria), Ph.D. Nuclear Physics (University of Surrey, Uk). 